\title{
CUSTO DE OPORTUNIDADE DA TERRA NO MANEJO DE BAIXO IMPACTO EM FLORESTAS TROPICAIS - UM ESTUDO DE CASO
}

\author{
Romano Timofeiczyk Junior*, Ricardo Berger*, Roberto Antonio Ticle de Melo e Sousa**, \\ Versides Sebastião de Moraes e Silva*** \\ *Eng. Florestal, Dr., Depto. de Economia Rural e Extensão, UFPR - romano@ufpr.br - berger@ufpr.br \\ **Eng. Florestal, Dr., Faculdade de Engenharia Florestal, UFMT - ratms@terra.com.br \\ ***Eng. Florestal, Dr., Faculdade de Engenharia Florestal, UFMT - versides@terra.com.br \\ Recebido para publicação: 22/09/2006 - Aceito para publicação: 04/06/2007
}

\begin{abstract}
Resumo
Este estudo teve o objetivo de analisar a influência do custo de oportunidade da terra na estrutura de custos do manejo de baixo impacto em florestas tropicais em dois ciclos de produção. Os dados foram obtidos em uma fazenda situada no município de Marcelândia, estado do Mato Grosso, que explora a floresta tropical sob regime de manejo e comercializa as toras para indústrias da região. Os resultados demonstraram elevação dos custos variáveis de $\mathrm{R} \$ 39,56 / \mathrm{m}^{3}$ para $\mathrm{R} \$ 43,09 / \mathrm{m}^{3}$ ao longo do primeiro ciclo em função da implantação dos tratos silviculturais, com o custo fixo permanecendo em R\$ $22,62 / \mathrm{m}^{3}$. No segundo ciclo, ocorreu redução no custo total em razão do aumento da produtividade para $15 \mathrm{~m}^{3} / \mathrm{ha}$ e da eliminação de operações das atividades pré-exploratória e exploratória, com o custo variável passando para $\mathrm{R} \$ 30,69$ e o custo fixo para $\mathrm{R} \$ 18,10 / \mathrm{m}^{3}$. Ao considerar os custos de oportunidade da terra, o custo fixo assumiu a maior parcela dos custos totais, com $\mathrm{R} \$ 45,99 / \mathrm{m}^{3}$ no primeiro ciclo e $\mathrm{R} \$ 34,37 / \mathrm{m}^{3}$ no segundo ciclo.

Palavras-chave: Custo da terra; floresta tropical; custos do manejo.
\end{abstract}

\begin{abstract}
Costs of land opportunity for low impact manegement in the tropical forest - a case study. This work had the objective of analyzing the influence of the land opportunity costs in the cost of low impact management in the tropical forest in two production cycles. The data utilized came from a company that explores a forest land localized in the Marcelândia city, state of Mato Grosso, and commercializes the logs with the industries of the region. The results showed the increasing of the variables costs of $\mathrm{R} \$ 39,56 / \mathrm{m}^{3}$ to $\mathrm{R} \$ 43,09 / \mathrm{m}^{3}$ a long the first cycle in function of the silvicultures treatments, with the same fixed costs in $\mathrm{R} \$ 22,62 / \mathrm{m}^{3}$. In the second cycle it was observed a reduction in the total cost due to the increasing of productivity to $15 \mathrm{~m}^{3} / \mathrm{ha}$, and the elimination of preharvesting and harvesting operations, with the average variable cost changing to $\mathrm{R} \$ 30.69$ and the average fixed cost to $\mathrm{R} \$ 18,10 / \mathrm{m}^{3}$. Taking into account the value of land opportunity costs, the average fixed cost was respectively the greatest share in the total costs, that is $R \$ 45.99 / \mathrm{m}^{3}$ and $\mathrm{R} \$$ $34.37 / \mathrm{m}^{3}$ in the first and second cycles.

Keywords: Low costs; tropical forest; structure of costs; costs of land opportunity.
\end{abstract}

\section{INTRODUÇÃO}

Conforme Arima e Veríssimo (2002), a Amazônia legal brasileira possui 5 milhões de km², dos quais 4 milhões, ou aproximadamente $80 \%$, são cobertos por densa floresta tropical, o que equivale a um volume estimado em 60 bilhões de metros cúbicos de madeira em tora, cujo valor econômico potencial pode alcançar R \$ 4 trilhões em madeira serrada. As áreas não-florestais, como cerrados e campos naturais, são de $19 \%$, enquanto lagos e rios compreendem 1\% da Amazônia.

Em função da sua biodiversidade, da importância que tem como reguladora do clima, na proteção de mananciais e dos solos, além de grande fornecedora de produtos madeireiros e nãomadeireiros, o manejo florestal sustentado passou a ser um importante instrumento para compatibilizar o desenvolvimento ambiental, social e econômico. Entretanto, embora as pesquisas sobre manejo florestal 
na Amazônia brasileira venham sendo desenvolvidas desde 1958, a descontinuidade dessas pesquisas não permite que se tenham ainda informações concretas envolvendo um ciclo completo de corte (SOUZA, 2002). Além disso, na prática é difícil definir o que se entende por manejo florestal sustentável. As interações entre flora e fauna em um ecossistema florestal são complexas e difíceis de entender, haja vista que ações tomadas no presente somente serão mostradas com mais evidências em sucessivos ciclos de corte, que é o período decorrido entre dois momentos de exploração na mesma área (CUNHA, 2003).

Para a realização do manejo em escala empresarial, são necessários altos investimentos numa série de recursos de produção, elevando o custo em termos de imobilização de terra, equipamentos e operação. O conhecimento desses custos é fundamental para o planejamento e a administração, bem como de extrema importância para se conhecer a eficiência econômica da empresa. Tais recursos podem ser classificados como fixos e variáveis, permitindo análises de curto e longo prazo. O curto prazo é o período de tempo em que a empresa não pode variar a quantidade de alguns recursos, ao passo que o longo prazo é o período de planejamento suficientemente longo para que a firma possa variar as quantidades de todos os recursos utilizados por unidade de tempo. As análises de custos aplicadas às empresas florestais sempre terão componentes fixos, portanto, de curto prazo, seja qual for o padrão de custos que adote (GRAÇA, 1997).

Entre os custos envolvidos na produção florestal, estão aqueles cuja avaliação técnico-econômica é de grande importância, como é o caso do custo de oportunidade da terra, que nada mais é do que a remuneração periódica e perpétua do capital investido nesse recurso por parte do processo produtivo. A terra é o capital básico de qualquer produtor florestal, sendo de relativa permanência e representando um alto investimento. Graça (1997) afirma que o economista está interessado nos detalhes dos custos fixos e variáveis e na estrutura de custos. Já aos produtores interessam os aspectos imediatos da produção, ligados aos custos variáveis, relegando a um segundo plano os custos fixos, em especial aqueles que estão ligados a custos de oportunidades. Em geral, pequenos produtores florestais têm pouco interesse em imputar custos de oportunidade à terra, e muitas vezes sequer conhecem o conceito. $\mathrm{O}$ mesmo autor salienta que esses produtores não vêem a terra como um bem conceitualmente disponível para obter remuneração alternativa, a não ser quando colocam eventualmente em arrendamento.

Hildebrand (1995) menciona que há na literatura opiniões contraditórias referentes à determinação dos custos do uso do recurso terra, que na atividade florestal é indispensável. Portanto, o perfeito detalhamento dos custos fixos, dos variáveis e do custo de oportunidade da terra é indispensável para o êxito do manejo florestal, tornando-se um requisito necessário para a busca da sustentabilidade. Nesse aspecto, o presente trabalho visa analisar a influência do custo de oportunidade da terra na estrutura de custos do manejo de baixo impacto.

\section{MATERIAL E MÉTODOS}

\section{Área de estudo}

A fazenda que gerou os dados para a realização desse trabalho está localizada no município de Marcelândia, estado do Mato Grosso, a $873 \mathrm{~km}$ de Cuiabá, e produz toras a partir de floresta tropical, tendo como principal destino da produção as indústrias de laminados e serrados dos municípios de Sinop e Marcelândia, no Mato Grosso. A sua descrição foi fornecida pelo Projeto de Apoio ao Manejo Florestal Sustentável na Amazônia (ProManejo) - MMA/IBAMA/PPG7, Projeto Huaia-Missu. A área total da Fazenda é de 145.000 ha, e a Área de Manejo Florestal (AMF) é de 116.348 ha. O tamanho de cada Unidade de Produção Anual (UPA), que é a área a ser explorada anualmente, é de 4.653,92 ha.

\section{Fonte de dados primários e secundários}

Os dados primários utilizados no trabalho, como as informações referentes aos recursos físicos e financeiros necessários para a execução do manejo florestal, foram fornecidos pela empresa responsável pela execução do manejo florestal e pela comercialização das toras. Já os dados secundários foram obtidos no Instituto Brasileiro do Meio Ambiente e dos Recursos Naturais Renováveis (IBAMA), Ministério do Meio Ambiente (MMA), Sindicato das Indústrias Madeireiras do Norte do Mato Grosso (SINDUSMAD) e Inflor - Engenharia Florestal. 


\section{Identificação das atividades e operações}

A realização do trabalho foi baseada na Instrução Normativa 04 do Ministério do Meio Ambiente (MMA), que regulamenta o manejo florestal em escala empresarial na região Amazônica, sendo considerados dois ciclos de corte de 25 anos cada um. A metodologia utilizada está representada na figura 1, na qual cada quadrado representa uma UPA, do total de 25 UPAs. No primeiro ciclo de corte são exploradas as UPAS de número 1 a 25, sendo considerado como implantação do sistema de manejo florestal. Após o início do segundo ciclo de corte, cujo sistema de manejo florestal já está implantado, retorna-se na primeira UPA, representada pela simbologia 1s. Esse procedimento repete-se ao longo dos anos.

\begin{tabular}{|c|c|c|c|c|c|c|c|c|c|}
\hline 1 & 2 & 3 & 4 & 5 & 6 & 7 & 8 & 9 & 10 \\
\hline 11 & 12 & 13 & 14 & 15 & 16 & 17 & 18 & 19 & 20 \\
\hline 21 & 22 & 23 & 24 & 25 & $1 \mathrm{~s}$ & $2 \mathrm{~s}$ & $3 \mathrm{~s}$ & $4 \mathrm{~s}$ & $5 \mathrm{~s}$ \\
\hline $6 \mathrm{~s}$ & $7 \mathrm{~s}$ & $8 \mathrm{~s}$ & $9 \mathrm{~s}$ & $10 \mathrm{~s}$ & $11 \mathrm{~s}$ & $12 \mathrm{~s}$ & $13 \mathrm{~s}$ & $14 \mathrm{~s}$ & $15 \mathrm{~s}$ \\
\hline $16 \mathrm{~s}$ & $17 \mathrm{~s}$ & $18 \mathrm{~s}$ & $19 \mathrm{~s}$ & $20 \mathrm{~s}$ & $21 \mathrm{~s}$ & $22 \mathrm{~s}$ & $23 \mathrm{~s}$ & $24 \mathrm{~s}$ & $25 \mathrm{~s}$ \\
\hline
\end{tabular}

Figura 1. Unidades de produção anual (UPA) nos dois ciclos de corte.

Figure 1. Annual production units in the two cutting cicles.

Para determinar os custos do manejo florestal, tornou-se necessário a subdivisão dos eventos que ocorrem no processo de produção de madeiras. Segundo Mendes e Hildebrand (1997), esses eventos podem ser especificados como "processos", "atividades", "operações" e "recursos de produção", e a atividade pode ser definida como sendo o conjunto de operações que demandam os recursos monetários e físicos para a produção de madeira, podendo ser classificada como componente do processo de produção. Conforme Mendes (1998), há recursos que variam com a produção e há outros que não dependem do nível de produção. Assim, no curto prazo, há recursos fixos e variáveis, sendo que os fixos são os que não variam em função das alterações de produção, enquanto os recursos variáveis são os que, necessariamente, se alteram com as variações de produção. A natureza dessas duas categorias de recursos conduz aos custos fixos e variáveis.

\section{Custos variáveis}

Para a execução do Plano de Manejo Florestal Sustentável (PMFS), é necessário elaborar o Plano Operacional Anual (POA), que deve conter todas as atividades florestais da empresa num determinado ano. Essas atividades formam os custos variáveis. Para determinar esses custos, considerou-se o gasto anual dessas atividades nos dois ciclos de corte analisados neste trabalho. O POA deve conter as seguintes atividades:

\section{Atividade pré-exploratória}

Para a obtenção do custo anual da atividade pré-exploratória, foram quantificados os custos das operações componentes dessa atividade, que são:

- Elaboração do Plano de Manejo Florestal Sustentado (PMFS), consistindo na confecção de mapas e inventário amostral;

- Censo florestal, que consiste na demarcação das unidades de trabalho (UTs), aberturas de picadas e mensuração, avaliação e mapeamento das árvores;

- Taxa do IBAMA (pré-exploratória);

- $\quad$ Corte de cipós. 
A elaboração do PMFS e o censo florestal são realizados por terceiros, com o pagamento efetuado por ha trabalhado, sendo que o valor gasto para a execução dessas operações foi fornecido pela empresa que executa o manejo da floresta. O censo florestal é uma operação importante, pois permite a localização, mensuração e avaliação das árvores de valor comercial, além de gerar informações úteis para o planejamento da exploração e das práticas silviculturais. Os custos da confecção de mapas, inventário amostral, demarcação das UTs, abertura de picadas, mensuração, avaliação e mapeamento das árvores foram obtidos junto à Inflor Engenharia Florestal, empresa que executa as operações acima citadas para empresas da região.

A taxa de vistoria prévia é realizada antes da aprovação do PMFS, e o valor a ser recolhido ao IBAMA foi obtido na sede desse órgão, no município de Sinop (MT). Para o cálculo do valor dessa taxa, cobra-se um valor fixo até 250 hectares, e recolhe-se uma taxa sobre cada hectare adicional. A operação de corte de cipós é realizada pela empresa responsável pelo manejo, que repassou os custos por ha.

\section{Atividade exploratória}

Para a obtenção do custo anual da atividade exploratória, quantificou-se os custos de todas as operações componentes dessa atividade, quais sejam:

- Taxas do IBAMA, como a taxa de acompanhamento e Autorização de Transporte de Produtos Florestais (ATPF);

- Operações de exploração, constituindo-se pela abertura de estradas secundárias e esplanadas, derrubada, arraste, traçamento e cubagem;

- Carregamento das toras nos caminhões.

A taxa de acompanhamento recolhida ao IBAMA é igual à taxa de vistoria prévia, já que ambas apresentam a mesma metodologia de cálculo. A Autorização de Transporte de Produtos Florestais (ATPF) é requisitada pela empresa por ocasião da aprovação do projeto de manejo, sendo que cada ATPF consiste em uma carga de $35 \mathrm{~m}^{3}$. As operações de exploração são realizadas por terceiros, com o pagamento sendo efetuado por metro cúbico esplanado (quantidade de madeira disponibilizada num pátio intermediário dentro da floresta, denominado de esplanada).

Para a determinação dos custos das operações de exploração, foram realizadas entrevistas com as empresas prestadoras desses serviços, chamadas de esplanadores, e com o gerente da empresa contratante. O carregamento das toras nas carretas também é executado por terceiros, com o pagamento sendo efetivado por metro cúbico carregado.

\section{Atividade pós-exploratória}

Pouco se conhece sobre os métodos silviculturais da maioria das espécies encontradas nos trópicos, sendo um fator limitante e conflitante para se criar um modelo único de manejo florestal. As projeções sobre as reais necessidades da adoção de práticas silviculturais antes e após a exploração são baseadas em pesquisas científicas, requerendo confirmações por meio de experimentos de longo prazo. Os resultados até agora obtidos mostram que esses procedimentos têm influência positiva no crescimento da floresta remanescente.

Para a obtenção do custo anual da atividade pós-exploratória, quantificaram-se os custos de todas as operações componentes dessa atividade:

- Proteção florestal;

- Monitoramento e desenvolvimento da floresta;

- Tratos silviculturais;

- Limpeza de estradas secundárias e esplanadas.

A proteção florestal visa proteger a propriedade de invasões, incêndios florestais, caça e pesca ilegal e o meio ambiente em geral. Essa operação é realizada na área total da Fazenda, e os custos anuais estimados para a sua execução foram repassados pela empresa responsável pelo manejo.

A introdução do monitoramento e desenvolvimento da floresta permite acompanhar o seu crescimento, mortalidade, regeneração, bem como os danos causados pela exploração. O intervalo de tempo adotado para a execução foi baseado no trabalho de Silva (1997), que considerou intervalo de cinco anos entre as medições. O custo da realização deste trabalho foi obtido junto à Inflor - Engenharia Florestal.

Os tratos silviculturais ocorrem apenas uma vez na UPA após a retirada da madeira. As operações de limpeza de estradas secundárias e esplanadas e o monitoramento do desenvolvimento da 
floresta são executados a cada cinco anos. A introdução da limpeza de estradas secundárias e esplanadas na atividade pós-exploratória foi baseada no trabalho de Silva (1997), no qual essa operação é realizada a cada cinco anos. De acordo com informações obtidas na empresa, o intervalo de tempo ideal para executar a operação é de 5 anos. Intervalos menores não se justificam em razão da baixa densidade, e intervalos maiores podem comprometer a operação, diminuindo a produtividade e aumentando o custo.

Impostos

Segundo Mendes e Hildebrand (1997), em função dos impostos serem indispensáveis no processo de produção, podem ser considerados como recursos, mesmo não gerando produção. Os mesmos autores citam que os impostos podem ser classificados como fixos ou variáveis.

Os impostos vinculados com a produção foram classificados como custo variável. De acordo com informações obtidas na empresa, esses impostos são: Imposto de Renda (IR), Contribuição Social sobre o Lucro Líquido (CSLL), Fundo de Assistência ao Trabalhador Rural (Funrural) e Instituto Nacional da Seguridade Social (INSS).

\section{Custos fixos}

Os recursos fixos utilizados no processo de produção de toras e a remuneração anual para manter esses recursos foram fornecidos pela empresa. Em razão da diferença de idade existente entre os vários bens móveis e imóveis, optou-se por utilizar o valor de aquisição desses bens. Os componentes dos custos fixos são:

- Imposto Territorial Rural (ITR);

- Depreciação;

- Juros sobre o Capital Próprio;

- Custos Administrativos, composto por salários e encargos, manutenção da sede da fazenda, manutenção de caminhões e máquinas, manutenção de veículos de apoio, manutenção de estradas principais e pontes, despesas administrativas e manutenção do escritório de Sinop.

- Custo de oportunidade da terra.

O Imposto Territorial Rural - ITR incide sobre a propriedade de bens imóveis situados na zona rural. A depreciação econômica representa a perda do valor dos ativos, resultante do desgaste pelo uso, ação da natureza ou por obsoletismo técnico, constituindo-se num importante componente dos custos de produção (LHORET, 1994). A depreciação visa apropriar o custo ou outro valor básico dos bens permanentes tangíveis, menos o valor residual (se houver), pela vida útil estimada do bem.

De acordo com Timofeiczyk Júnior (2004), diversos métodos são utilizados para o cálculo da depreciação, porém, para esse trabalho, optou-se pelo critério de depreciação linear, largamente utilizado na literatura econômica. A metodologia de cálculo para a obtenção desse item de custo se encontra abaixo:

onde: $\mathrm{De}=$ Depreciação $(\mathrm{R} \$ / \mathrm{ano})$;

$$
D e=(V \cdot A-V \cdot R .) / V \cdot u
$$

$\mathrm{V} . \mathrm{A}=$ Valor de aquisição $(\mathrm{R} \$)$;

$\mathrm{V} . \mathrm{R}=$ Valor residual $(\mathrm{R} \$)$;

V.u $=$ Vida útil (anos).

A remuneração do capital próprio representa o custo do valor perdido pela não aplicação na melhor alternativa econômica. Segundo Hildebrand (1995), esse juro é calculado por meio da seguinte fórmula:

$$
R C=V A .\left((1+i)^{n} . i\right) /\left((1+i)^{n}-1\right)-D
$$

onde: $\mathrm{RC}=$ Remuneração do capital $(\mathrm{R} \$)$;

$\mathrm{VA}=$ Valor presente da aplicação ou aquisição (R\$);

$\mathrm{i}=$ Taxa de desconto anual (\%);

$\mathrm{D}=$ Depreciação anual $(\mathrm{R} \$)$;

$\mathrm{n}=$ Tempo (anos). 
Com exceção de D, a fórmula acima é utilizada para série uniforme de pagamentos ou recebimentos. A taxa de juros utilizada para a remuneração do capital próprio é estimada em função das alternativas de aplicação ao alcance da empresa (HILDEBRAND, 1995). Os outros custos que não possuem vínculo direto com a produção foram alocados como custo administrativo.

Segundo Rezende et al. (1994), a terra é o capital básico de qualquer produtor florestal, e no levantamento de cada componente de custos e receitas envolvidos no processo de produção, o custo de oportunidade da terra é de grande importância para a avaliação econômica. A função do custo de oportunidade da terra pode ser dada por:

$$
C T=V C . T X
$$

onde: $\mathrm{CT}=$ Custo de oportunidade da terra $(\mathrm{R} \$ / \mathrm{ha})$; $\mathrm{VC}=$ Valor de mercado da terra, por hectare; $\mathrm{TX}=$ Taxa anual de remuneração da terra $(\%)$.

Para o presente trabalho, a taxa de remuneração adotada como custo de oportunidade da terra foi de 3\% ao ano. Esse valor é recomendado por Turra (1990), que afirma não haver justificativa para o uso de outros valores, baseado em estudos econômicos da agricultura brasileira, uma vez que a terra é um ativo de baixa liquidez, ou seja, não é um bem que rapidamente possa ser convertido em aplicações mais rentáveis.

O preço da terra na região foi fornecido pela empresa objeto deste estudo. A fim de confirmar os valores, foi realizada uma nova consulta com o Sindusmad e Inflor - Engenharia Florestal. A taxa de juros utilizada para a remuneração do capital próprio é estimada em função das alternativas de aplicação ao alcance da empresa. Nesse estudo, a taxa de juros adotada para a determinação desse custo foi de $12 \%$ ao ano, baseada no trabalho de Timofeiczyk Júnior (2004). Os outros custos que não possuem vínculo direto com a produção foram alocados como custo administrativo.

\section{Participação dos componentes de custos do manejo florestal}

Após o levantamento dos custos de produção, foram obtidos os seguintes resultados:

a) Quantificação monetária e em percentual dos custos fixos e variáveis totais que ocorreram no primeiro e segundo ciclos;

b) Quantificação monetária e em percentual dos componentes dos custos fixos e dos custos variáveis;

c) Impacto da inclusão do custo de oportunidade da terra na estrutura de custos do manejo florestal.

Para a estimativa do volume disponível no segundo ciclo de corte, considerou-se que o crescimento das árvores aumentaria por meio da implantação dos tratos silviculturais. Amaral et al. (1998) afirmam que o acréscimo de volume a ser explorado no segundo ciclo, em função dos tratos silviculturais, é de $16 \%$. No caso da floresta objeto deste estudo, a produção atual é de $12 \mathrm{~m}^{3} / \mathrm{ha}$, com a estimativa de colheita aumentando para $15 \mathrm{~m}^{3} /$ ha no segundo ciclo, em função da implantação dos tratos silviculturais. No segundo ciclo de corte, para determinar o volume comercializado por espécie, considerou-se o mesmo percentual do primeiro ciclo.

\section{RESULTADOS}

\section{Custos variáveis e fixos sem o custo de oportunidade da terra}

As Unidades de Produção Anual (UPAs) estão sofrendo a primeira intervenção florestal, e o atual nível de operação e comercialização é de $12 \mathrm{~m}^{3} /$ ha distribuídos em várias espécies. O custo variável foi responsável por $63,6 \%$ dos custos totais no início do primeiro ciclo de corte. A sua participação aumentou para $65,6 \%$ ao final deste, enquanto o custo fixo reduziu de $36,4 \%$ para $34,4 \%$ no final do ciclo (Figura 2). Essa elevação do custo variável no primeiro ciclo ocorreu em função da implantação da atividade pós-exploratória nas Unidades de Produção Anual (UPAs). Em termos monetários, o custo variável por metro cúbico elevou-se de $\mathrm{R} \$ 39,56$ para $\mathrm{R} \$ 43,09$ no decorrer do primeiro ciclo, enquanto o custo fixo permaneceu em $\mathrm{R} \$ 22,62$, com o custo médio de produção passando de $\mathrm{R} \$ 62,18 / \mathrm{m}^{3}$ para $\mathrm{R} \$$ 
$65,71 / \mathrm{m}^{3}$ no primeiro ciclo (Figura 3 ).

No segundo ciclo, a participação dos custos variáveis nos custos totais reduziu para $64 \%$, enquanto os custos fixos aumentaram para $36 \%$. Em termos monetários, os custos variáveis reduziram de $\mathrm{R} \$ 43,09$ para $\mathrm{R} \$ 32,22$, representando uma diminuição de $25,23 \%$ (Figura 3). Isso ocorreu em função de algumas operações das atividades pré-exploratória e exploratória que deixaram de ser executadas, como o inventário amostral, demarcação das UTs e abertura de estradas secundárias e esplanadas. Já o custo fixo passou de $\mathrm{R} \$ 22,62 / \mathrm{m}^{3}$ no primeiro ciclo de corte para $\mathrm{R} \$ 18,10 / \mathrm{m}^{3}$ no segundo ciclo, representando redução de $18,54 \%$, ocasionado pelo aumento do volume de $12 \mathrm{~m}^{3} /$ ha para $15 \mathrm{~m}^{3} /$ ha (Figura 3). O custo médio por metro cúbico foi reduzido para $\mathrm{R} \$ 50,32$, representando uma queda de $23,42 \%$.

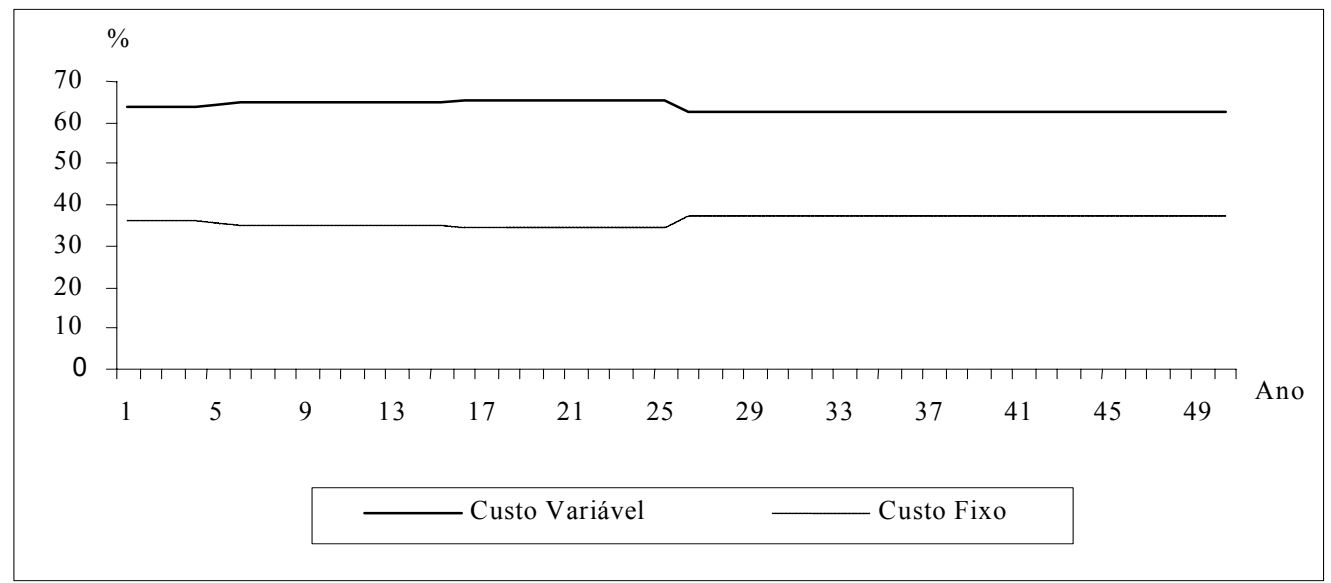

Fonte: Timofeiczyk Júnior et al., 2005.

Figura 2. Participação percentual dos custos fixos e variáveis no custo total nos dois ciclos de corte. Figure 2. Percentage participation of fixed and variables costs in the total cost for two cutting cicles.

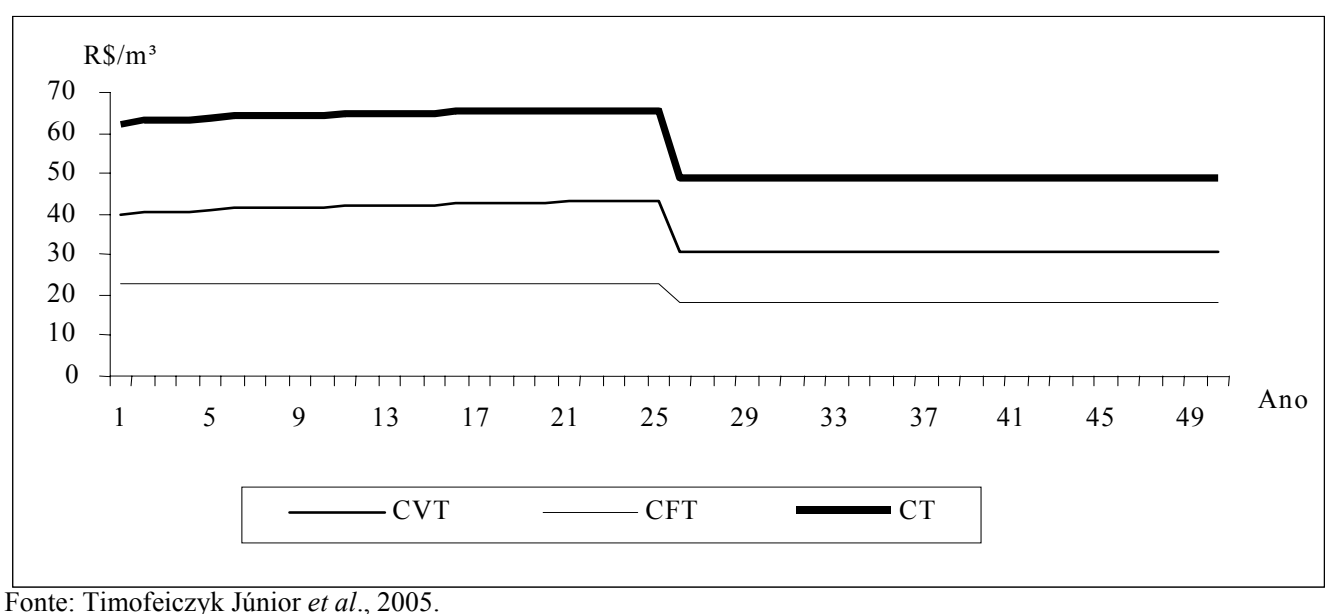

Figura 3. Custo total médio, custo fixo médio e custo variável médio por metro cúbico nos dois ciclos de corte $\left(\mathrm{R} \$ / \mathrm{m}^{3}\right)$.

Figure 3. Average total cost, average fixed cost and average variable cost per cubic meter for two cutting cicles $\left(\mathrm{R} \$ / \mathrm{m}^{3}\right)$. 


\section{Análise dos custos variáveis \\ Atividade pré-exploratória}

$\mathrm{O}$ custo da atividade pré-exploratória no primeiro ciclo de corte foi de $\mathrm{R} \$ 5,34 / \mathrm{m}^{3}$, o que corresponde a $8,6 \%$ do custo total de produção (Tabela 1), mostrando a baixa participação dessa atividade no custo do manejo de baixo impacto. No final do primeiro ciclo, o custo da atividade em relação ao custo total foi reduzido em $8,1 \%$, em razão do aumento dos custos no primeiro ciclo de corte, resultante da implantação dos tratos silviculturais na atividade pós-exploratória.

Das operações dessa atividade, o censo florestal foi a mais onerosa, sendo responsável por 6,3\% do custo total do manejo no primeiro ciclo (Tabela 1). Conforme Timofeiczyk Júnior et al. (2005), no mesmo nível de operação, no censo florestal a mensuração, a avaliação e o mapeamento das árvores apresentam um custo de $\mathrm{R} \$ 1,92 / \mathrm{m}^{3}$, representando $35,95 \%$ dos custos dessa atividade.

No segundo ciclo de corte, o custo dessa atividade diminuiu de $\mathrm{R} \$ 5,34 / \mathrm{m}^{3}$ para $\mathrm{R} \$ 3,49 / \mathrm{m}^{3}$, com a participação no custo total passando de $8,6 \%$ para 6,9\%. Segundo Timofeiczyk Júnior et al. (2005), a confecção de mapas, inventário amostral e demarcação do talhão são dispensáveis no segundo ciclo por já terem sido implantadas no primeiro. Aliado a isso, salienta-se a elevação da produção para $15 \mathrm{~m}^{3}$.

Tabela 1. Participação das etapas da atividade pré-exploratória no custo total e unitário nos dois ciclos de corte.

Table 1. Participation of the phases of pre-exploratory activity in the total and unit cost for two cutting cicles.

\begin{tabular}{lcccc}
\hline \multirow{2}{*}{ Pré-exploratória } & \multicolumn{2}{c}{$\mathbf{R} \$ \mathbf{m}^{\mathbf{3}}$} & \multicolumn{2}{c}{$\%$ do custo total } \\
\cline { 2 - 5 } & $\mathbf{1}^{\mathbf{0}}$ Ciclo & $\mathbf{2}^{\mathbf{0}}$ Ciclo & $\mathbf{1}^{\mathbf{0}}$ Ciclo & $\mathbf{2}^{\mathbf{0}}$ Ciclo \\
\hline Elaboração do PMFS & 0,67 & & 1,1 & \\
Censo Florestal & 3,91 & 2,88 & 6,3 & 5,7 \\
Taxa do IBAMA & 0,05 & 0,04 & 0,1 & 0,1 \\
Corte de cipós & 0,71 & 0,57 & 1,1 & 1,1 \\
Total & 5,34 & 3,49 & 8,6 & 6,9 \\
\hline
\end{tabular}

Fonte: Timofeiczyk et al., 2005.

\section{Atividade exploratória}

A atividade exploratória foi a que apresentou o maior custo de produção, com $\mathrm{R} \$ 22,33 / \mathrm{m}^{3}$ no primeiro ciclo (Tabela 2). Em função da implantação dos tratos silviculturais na atividade pósexploratória, a participação percentual dessa atividade no custo total reduziu de $35,9 \%$ para $34,0 \%$ no decorrer do primeiro ciclo. A atividade exploratória custou $\mathrm{R} \$ 19,00 / \mathrm{m}^{3}$, representando $85,2 \%$ do custo da atividade. Dos custos da atividade exploratória, $57,8 \%$ são das operações de abertura de estradas e arraste (TIMOFEICZYK JÚNIOR et al., 2005). Ainda de acordo com esses autores, no segundo ciclo, nas operações de exploração, a demarcação e abertura de estradas secundárias e esplanadas não são executadas, em virtude de já terem sido implementadas no primeiro ciclo. A não-execução dessas operações ocasionou uma diminuição nos custos de exploração de $38,33 \%$, reduzindo o custo de R $\$$ $22,33 / \mathrm{m}^{3}$ para $\mathrm{R} \$ 13,79 / \mathrm{m}^{3}$ (Tabela 2). Ressalte-se que o cronograma da atividade pós-exploratória contempla, a cada cinco anos, a manutenção das estradas secundárias e esplanadas.

Tabela 2. Participação das operações da atividade exploratória no custo unitário e total nos dois ciclos de corte.

Table 2. Participation of the exploratory activity operations in the total and unit cost for two cutting cicles.

\begin{tabular}{lcccc}
\hline \multirow{2}{*}{ Exploratória } & \multicolumn{2}{c}{$\mathbf{R} \$ \mathbf{m}^{\mathbf{3}}$} & \multicolumn{2}{c}{$\%$ do custo total } \\
\cline { 2 - 5 } & $\mathbf{1}^{\mathbf{0}}$ Ciclo & $\mathbf{2}^{\mathbf{0}}$ Ciclo & $\mathbf{1}^{\mathbf{0}}$ Ciclo & $\mathbf{2}^{\mathbf{0}}$ Ciclo \\
\hline Taxas do IBAMA & 0,33 & 0,34 & 0,6 & 0,6 \\
Operações de exploração & 19,00 & 10,45 & 30,5 & 20,8 \\
Carregamento & 3,00 & 3,00 & 4,8 & 6,0 \\
Total & 22,33 & 13,79 & 35,9 & 27,4 \\
\hline
\end{tabular}

Fonte: Timofeiczyk et al., 2005. 


\section{Atividade pós-exploratória}

Algumas operações dessa atividade ocorrem apenas uma vez na UPA após a intervenção na floresta, como o favorecimento de espécies remanescentes, liberação da regeneração natural e corte de cipós (TIMOFEICZYK JÚNIOR et al., 2005). Ainda conforme os mesmos autores, a limpeza de estradas secundárias e esplanadas, assim como o monitoramento e desenvolvimento da floresta ocorrem em intervalos de cinco anos, implicando a inserção de uma nova UPA no cronograma operacional dentro desse prazo. Essas oscilações no cronograma das atividades pós-exploratórias, em que são executadas as operações necessárias a cada cinco anos, elevou o custo total do manejo no primeiro ciclo.

É possível verificar, pela tabela 3, que a participação da atividade pós-exploratória no custo unitário total elevou-se de $1,4 \%$ no início do primeiro ciclo de corte para $6,7 \%$ ao final dele, elevando-se de $\mathrm{R} \$ 0,89 / \mathrm{m}^{3}$ para $\mathrm{R} \$ 4,42 / \mathrm{m}^{3}$. No segundo ciclo, em função do aumento da produção, o custo unitário da atividade reduziu para $\mathrm{R} \$ 3,96 / \mathrm{m}^{3}$. Entretanto, a participação relativa no custo total elevou-se para $7,9 \%$, em razão da redução dos custos das atividades pré-exploratória e exploratória, aumentando a participação da atividade pós-exploratória no custo total.

Tabela 3. Evolução do custo da atividade pós-exploratória no custo total e unitário.

Table 3. Evolution of the cost of post-exploratory activity in the total and unit cost.

\begin{tabular}{lcc}
\hline Ano & $\mathbf{R} \mathbf{S} \mathbf{m}^{\mathbf{3}}$ & \% do custo total \\
\hline 1 & 0,89 & 1,4 \\
2 & 1,61 & 2,5 \\
6 & 2,85 & 4,4 \\
11 & 3,38 & 5,2 \\
16 & 3,91 & 6,0 \\
21 & 4,42 & 6,7 \\
26 & 3,96 & 7,9 \\
51 & 3,96 & 7,9 \\
\hline Fonte: Timofeiczyk Júnior et al., 2005 &
\end{tabular}

Impostos

Os valores pagos em impostos foram de $\mathrm{R} \$ 11,00 / \mathrm{m}^{3}$, sendo que no primeiro ciclo representaram $28 \%$ do custo variável médio e $18 \%$ do custo total médio. No segundo ciclo, a participação dos impostos no custo variável médio aumentou para $34,2 \%$, representando $22 \%$ do custo médio de produção nesse ciclo.

\section{Custos fixos}

É possível verificar que o custo fixo e seus componentes diminuíram a participação percentual no final do primeiro ciclo de corte, apesar de monetariamente não terem sofrido alterações. A implantação da atividade pós-exploratória no decorrer do primeiro ciclo promoveu o aumento dos custos variáveis, e conseqüentemente do custo total de produção, ocasionando a diminuição percentual dos custos fixos. $\mathrm{O}$ custo administrativo reduziu a sua participação no custo total de $26,2 \%$ para $24,7 \%$ no final do primeiro ciclo, porém o custo por unidade de produto permaneceu em $\mathrm{R} \$ 16,27 / \mathrm{m}^{3}$ (Tabela 4).

O custo administrativo, no primeiro ciclo, foi de $\mathrm{R} \$ 16,27 / \mathrm{m}^{3}$, representando $71,9 \%$ do custo fixo total, notando-se a sua grande participação no custo fixo da empresa e conseqüentemente no custo total. A depreciação da infra-estrutura, máquinas e equipamentos, juro sobre o capital investido e o Imposto Territorial Rural (ITR) oneraram a madeira em R $\$ 6,35 / \mathrm{m}^{3}$, representando $28,1 \%$ do custo fixo total (Tabela 4).

Tabela 4. Custo fixo unitário no primeiro ciclo de corte $\left(\mathrm{R} \$ / \mathrm{m}^{3}\right)$.

Table 4. Fixed unitary cost in the first cutting cicle $\left(\mathrm{R} \$ / \mathrm{m}^{3}\right)$.

\begin{tabular}{lcccc}
\hline \multirow{2}{*}{ Itens de custos } & \multirow{2}{*}{ Custo $\left(\mathbf{R} \$ \mathbf{m}^{\mathbf{3}}\right)$} & \multirow{2}{*}{ \% do custo fixo } & \multicolumn{2}{c}{$\%$ do custo total } \\
\cline { 4 - 5 } & & & Início do ciclo & Final do ciclo \\
\hline Custo Administrativo & 16,27 & 71,9 & 26,2 & 24,7 \\
Depreciação & 3,01 & 13,3 & 4,8 & 4,6 \\
Juros & 2,41 & 10,7 & 3,9 & 3,7 \\
ITR & 0,93 & 4,1 & 1,5 & 1,4 \\
Total & 22,62 & 100,0 & 36,4 & 34,4 \\
\hline
\end{tabular}

Fonte: Timofeiczyk Júnior et al., 2005. 
No segundo ciclo, houve decréscimo no custo fixo unitário para $\mathrm{R} \$ 18,10 / \mathrm{m}^{3}$, em razão do aumento do volume comercializado de $12 \mathrm{~m}^{3} /$ ha para $15 \mathrm{~m}^{3} /$ ha (Tabela 5). Entretanto, a participação percentual do custo fixo em relação ao custo total aumentou para $36 \%$, mantendo-se constante ao longo desse ciclo. Apesar do aumento da produção ter diluído os custos fixos por uma quantidade maior de produto, proporcionalmente essa redução foi menor que a respectiva redução nos custos variáveis, já que algumas operações das atividades pré-exploratória e exploratória deixaram de ser executadas no segundo ciclo.

Segundo Timofeiczyk Júnior et al. (2005), dos componentes do custo administrativo, os salários e a manutenção das estradas principais apresentaram os maiores custos, tanto no primeiro como no segundo ciclo de corte. No primeiro ciclo, esses dois componentes juntos responderam por $57,0 \%$ do custo fixo e $20,8 \%$ do custo total de produção. No segundo ciclo, em função do aumento da produção, os custos administrativos foram reduzidos em $20 \%$, passando para $\mathrm{R} \$ 13,02 / \mathrm{m}^{3}$.

Tabela 5. Custo fixo unitário no segundo ciclo de corte $\left(\mathrm{R} \$ / \mathrm{m}^{3}\right)$.

Table 5. Fixed unitary cost in the second cutting cycle $\left(\mathrm{R} \$ / \mathrm{m}^{3}\right)$.

\begin{tabular}{lccc}
\hline Itens de custos & Custo $\left(\mathbf{R} \mathbf{/ \mathbf { m } ^ { \mathbf { 3 } }}\right)$ & \% do custo fixo & \% do custo total \\
\hline Custo Administrativo & 13,01 & 71,9 & 25,9 \\
Depreciação & 2,41 & 13,3 & 4,8 \\
Juros & 1,92 & 10,7 & 3,8 \\
ITR & 0,76 & 4,1 & 1,5 \\
Total & 18,10 & 100,0 & 36,0 \\
\hline
\end{tabular}

Fonte: Timofeiczyk Júnior et al., 2005.

\section{Análise dos custos considerando o custo de oportunidade da terra}

A consideração do custo de oportunidade da terra, que é a remuneração periódica e definitiva do montante investido nesse recurso, ocasionou um grande impacto no custo fixo do manejo, refletindo diretamente no custo total de produção. Com a produção de $12 \mathrm{~m}^{3} /$ ha no primeiro ciclo, e aumento para $15 \mathrm{~m}^{3} /$ ha no segundo ciclo em razão da implantação dos tratos silviculturais, os custos fixos foram responsáveis por $36,4 \%$ dos custos no início do primeiro ciclo, diminuindo sua participação para $34,4 \%$ ao final dele, não considerando o custo de oportunidade da terra.

Entretanto, ao alocar esse custo, a participação dos custos fixos na composição do custo total aumentou para 53,8\% no início do primeiro ciclo, reduzindo para 51,6\% ao final dele (Figura 4). Em relação ao custo variável, a inclusão do custo de oportunidade da terra reduziu a sua participação nos custos totais de $63,6 \%$ para $46,2 \%$ no início do primeiro ciclo, e de $65,6 \%$ para $48,4 \%$ no final do ciclo.

No segundo ciclo de produção, o custo fixo foi responsável por 53,3\% dos custos totais, e o custo variável, por $46,7 \%$. Essa diminuição percentual do custo variável em relação ao custo total foi em função da redução do número de operações necessárias para a execução do manejo, aliado ao aumento da produtividade para $15 \mathrm{~m}^{3} /$ ha (Figura 4 ).

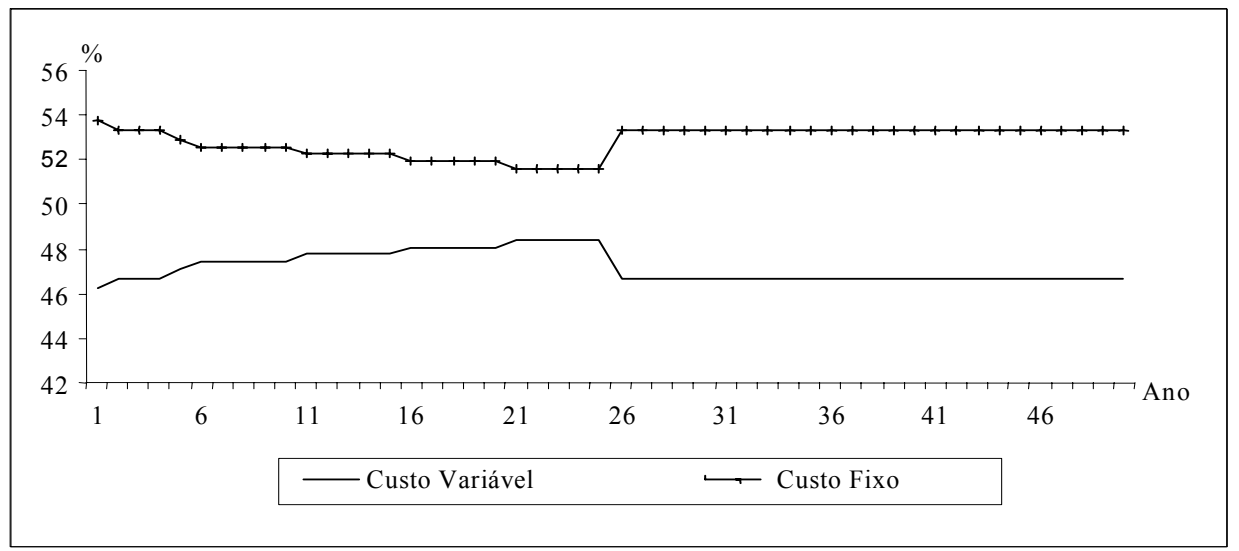

Figura 4. Participação dos custos fixos e variáveis nos dois ciclos de produção considerando o custo de oportunidade da terra $(\%)$.

Figure 4. Participation of fixed and variables costs in the total cost for two cutting cicles considering the land opportunity cost (\%). 
Na figura 5 é apresentado o comportamento do custo fixo médio, variável médio e custo médio, em reais, nos dois ciclos de produção analisados, considerando o custo de oportunidade da terra. Em função da inclusão desse custo, observou-se uma inversão na posição das curvas de custo fixo médio e variável médio, esta ficando abaixo daquela. Na situação em que não foi considerado o custo de oportunidade da terra, o custo variável médio apresentou-se maior que o custo fixo médio.

Em razão da elevação no custo da atividade pós-exploratória, de $\mathrm{R} \$ 0,89$ para $\mathrm{R} \$ 4,42 / \mathrm{m}^{3}$ no decorrer do primeiro ciclo, o custo médio aumentou de $\mathrm{R} \$ 85,55 / \mathrm{m}^{3}$ para $\mathrm{R} \$ 89,08 / \mathrm{m}^{3}$. No segundo ciclo, o custo médio reduziu para $\mathrm{R} \$ 69,01 / \mathrm{m}^{3}$, em razão do aumento da produtividade e da eliminação de operações das atividades pré e pós-exploratória (Figura 5).

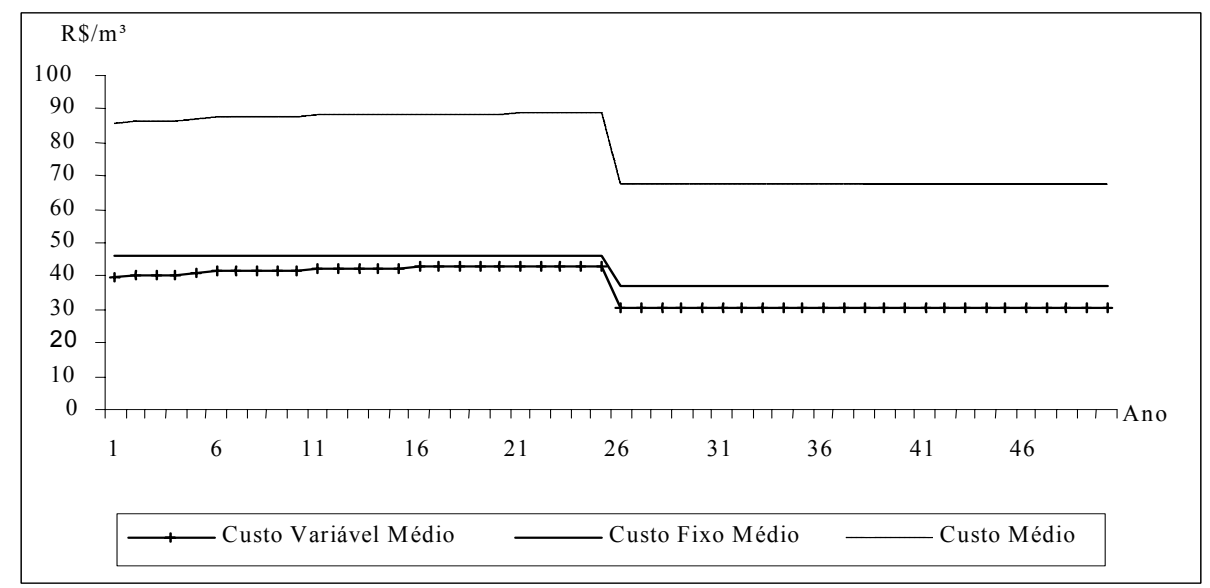

Figura 5. Comportamento dos custos unitários nos dois ciclos de produção considerando o custo de oportunidade da terra $\left(\mathrm{R} \$ / \mathrm{m}^{3}\right)$.

Figure 5. Behavior of the unitary costs for the two cutting cicles considering the land opportunity cost $\left(\mathrm{R} \$ / \mathrm{m}^{3}\right)$.

A consideração do custo de oportunidade da terra elevou o custo fixo médio de $\mathrm{R} \$ 22,62 / \mathrm{m}^{3}$ para $\mathrm{R} \$ 45,99 / \mathrm{m}^{3}$ (Tabela 6), dos quais 50,8\% referem-se a esse custo. Apesar de não ter havido alteração no valor absoluto dos componentes do custo fixo, o percentual em relação ao custo total alterou-se significativamente. $\mathrm{O}$ custo administrativo que, sem a inclusão do custo de oportunidade da terra, foi responsável por $71,9 \%$ do custo fixo no primeiro ciclo, com a consideração desse custo teve a sua participação no custo fixo reduzida para $35,4 \%$.

Tabela 6. Custo fixo unitário nos dois ciclos de produção considerando o custo de oportunidade da terra $\left(\mathrm{R} \$ / \mathrm{m}^{3}\right)$.

Table 6. Fixed unitary cost for two cutting cicles considering the land opportunity cost $\left(\mathrm{R} \$ / \mathrm{m}^{3}\right)$.

\begin{tabular}{lcc}
\hline Componentes do custo fixo & $\mathbf{1}^{\mathbf{0}}$ ciclo $\mathbf{( \mathbf { R } \$ \mathbf { m } ^ { \mathbf { 3 } } )}$ & $\mathbf{2}^{\mathbf{0}} \mathbf{\text { ciclo }}\left(\mathbf{R} \mathbf{\mathbf { S }} \mathbf{m}^{\mathbf{3}}\right)$ \\
\hline Custo de oportunidade da terra & 23,37 & 18,69 \\
Custo Administrativo & 16,27 & 13,01 \\
Juro sobre o capital investido & 2,41 & 1,92 \\
Depreciação & 3,01 & 2,41 \\
Imposto Territorial Rural & 0,93 & 0,75 \\
Total & 45,99 & 34,37 \\
\hline
\end{tabular}

\section{CONCLUSÕES}

- Sem considerar o custo de oportunidade da terra, o custo variável apresentou-se como o principal componente do custo total, elevando-se ao longo do primeiro ciclo de produção. Essa elevação ocorre em função da realização da atividade pós-exploratória. 
- No segundo ciclo de corte, os custos variáveis apresentaram redução em razão do aumento de $25 \%$ na produtividade, aliado ao fato de que várias operações das atividades pré-exploratória e exploratória que foram executadas no primeiro ciclo não ocorreram a partir do segundo ciclo.

- O custo fixo no primeiro ciclo ficou inalterado monetariamente, entretanto a sua participação percentual no custo total apresentou redução em razão do aumento do custo variável. No segundo ciclo, o aumento da produção diluiu os custos fixos por uma quantidade maior de produto, porém essa redução foi menor que a respectiva redução nos custos variáveis, em função das operações das atividades pré-exploratória e exploratória que deixaram de ser executadas no segundo ciclo.

- A consideração do custo de oportunidade da terra altera a estrutura de custos do manejo. Verifica-se inversão na posição da curva de custo fixo médio e custo variável médio, indicando uma maior participação dos custos fixos.

\section{REFERÊNCIAS}

AMARAL, P.; VERÍSSIMO, A.; BARRETO, P.; VIDAL, E. Floresta para sempre: um manual para a produção de madeira na Amazônia. Belém: Imazon, 1998. 130 p.

ARIMA, E.; VERÍSSIMO, A. Brasil em ação: ameaças e oportunidades econômicas na fronteira Amazônica. Belém: Imazon, 2002. 24 p. (Série Amazônica, n.19).

CUNHA, U. S. Análise da estrutura espacial horizontal de uma floresta de terra firme da Amazônia. 126 f. Tese. (Doutorado em Ciências Florestais) - Setor de Ciências Agrárias, Universidade Federal do Paraná, Curitiba, 2003,

GRAÇA, L. R. Elementos de custos de produção florestal: apropriações a análises. Curitiba: Fupef Silviconsult Engenharia, 1997. p. 1-21.

HILDEBRAND, E. Sistema de apropriação e análise de custos para a empresa florestal. 145 f. Dissertação (Mestrado em Ciências Florestais) - Setor de Ciências Agrárias, Universidade Federal do Paraná, Curitiba, 1995.

LHORET, L. Depreciação uma estratégia para se manter a competitividade. 94 f. Dissertação (Mestrado em Administração) - Setor de Ciências Sociais Aplicadas, Universidade Federal do Paraná, Curitiba, 1994

MENDES, J. T. G. Economia agrícola - princípios básicos e aplicações. 2 ed. Curitiba: ZNT, 1998.

MENDES, J. B.; HILDEBRAND, E. Procedimentos para a concepção de um sistema de custos florestais. Curitiba: Fupef - Silviconsult Engenharia, 1997. p. 1-26.

REZENDE, J. L. P.; LOPES, H. V. S.; NEVES, A. R.; PAULA JUNIOR, G. G. A importância do custo da terra na determinação da idade ótima de corte de povoamentos de Eucalyptus. Revista Árvore, Viçosa, MG, v. 18, n. 1, p. 45-55, 1994.

SILVA, Z. A. G. P. Análisis econômico del manejo forestal em el estado de Acre, Brasil. In: Simpósio Internacional Posibilidades de Manejo Forestal Sostenible em América Tropical, 1997, Santa Cruz de la Sierra, Bolívia. [Annales...]. [S.1.: s.n.], 1997. 11 p.

SOUZA, A. L. P. Desenvolvimento sustentável, manejo florestal e o uso dos recursos madeireiros na Amazônia: desafios, possibilidades e limites. Belém: UFPA/NAEA, 2002. 255 p.

TIMOFEICZYK JUNIOR, R. Análise econômica do manejo de baixo impacto em florestas tropicais - um estudo de caso. 126 f. Tese (Doutorado em Engenharia Florestal) - Setor de Ciências Agrárias, Universidade Federal do Paraná, Curitiba, 2004.

TIMOFEICZYK JUNIOR, R.; GRAÇA, L. R.; BERGER, R.; SOUSA, R. A. T. M.; HOSOKAWA, R. T. Estrutura de custos do manejo de baixo impacto em florestas tropicais - um estudo de caso. Revista Floresta, Curitiba, v. 35, n. 1, jan.abr., 2005.

TURRA, F. E. Análise de diferentes métodos de cálculo de custos de produção na agricultura brasileira. Curitiba: OCEPAR, 1990, 86 p. 